\title{
Preventing and removing wax deposition inside vertical wells: a review
}

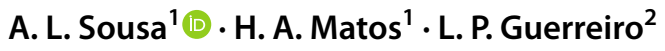

Received: 6 September 2018 / Accepted: 8 January 2019 / Published online: 21 January 2019

(c) The Author(s) 2019

\begin{abstract}
Wax deposition is one of the most challenging flow assurance issues in oil production processes. The related problems span from reservoirs to refineries, but their consequences can be particularly challenging when the affected area is difficult to reach, such as producing wells. The wax deposition in the areas adjoining the bore, the bore face, the tubing string and the pump is the result of the cooling effect, which occurs when the oil flows from the high-pressure reservoir into the wellbore to the surface. During the depressurization the oil expands, and the heat is drawn from the oil. The temperature loss induces crystallization of the wax and the subsequent plugging of the well. In this case, wax deposition leads to the decrease of well flow rates and eventually causes total blockage. This paper sums up the main technologies applied to prevent or remediate the wax deposition formed inside the wells. A comprehensive review was presented, and the main advantages and disadvantages of these techniques were highlighted. For instance, the mechanical removal is still a widely used technique for solving wax problems inside wells, despite being a costly procedure; heating is another frequent used technique, but it can cause formation damage; bacterial treatments still require further studies on site conditions; changing the operational conditions may be undesirable due to other management field circumstances; coating and insulating materials generally are not fully efficient, being required to implement complementary techniques; cold flow was only tested in pipelines and it was not applicable to wells; finally WIT, electric and magnetic field or oscillatory motion are practical applications that have not been fully proven yet.
\end{abstract}

Keywords Wax deposition inside wells · Wax prevention techniques and wax removal techniques

\section{Introduction}

Crude oil infrastructures are affected by wax depositions, both in pipelines and wells. Once precipitated, paraffin wax tends to agglomerate peripherally to the flow, next to its physical frontiers, leading to sectional decrease or, even, flow blockage.

As the flow temperature decreases below the cloud point (temperature below which wax forms a cloudy appearance) or wax appearance temperature (WAT), wax precipitation can occur. This phenomenon hinders flow by triggering non-Newtonian behaviour. The crude viscosity exponentially increases as the temperature reaches the pour point

A. L. Sousa

ana.margarida.sousa@tecnico.ulisboa.pt

1 CERENA/DEQ/IST-Universidade de Lisboa, Lisbon, Portugal

2 Partex Oil and Gas, Lisbon, Portugal (temperature below which liquid becomes semi-solid and loses its flow characteristics). Consequently, a layer of sticky freshly precipitated paraffin waxes begins to develop by the flow peripheral frontiers. Over time, the crystallized wax particles aggregate to form a continuously growing paraffinic layer.

Numerous studies about wax deposition formation, prevention and removal were performed along the past several decades. However, a blatant majority of those studies has been focused in pipelines (Bern et al. 1980; Banki et al. 2008; Azarinezhad et al. 2010; Wang and Huang 2014; Hu et al. 2015; Jalalnezhad and Kamali 2016; White et al. 2017), rather than wells. Such a circumstance is due to easiness in theoretically formulating, laboratory testing and real case monitoring of wax deposition in more accessible pipelines. Likewise, the location of pipelines at the production and transport extremities, frequently through subsea installations, make it more prone to experience lower temperatures and enhance the wax deposition probabilities (Quenelle and Gunaltun 1987). 
Nevertheless, wax deposits in wells do exist and pose a more complex problem to solve. Indeed, the theoretical formulation to describe it needs to recognize the complex well geometry, with multiple entries and sectional changes along length, as well as the effects of different artificial lifting methods. Furthermore, most of the preventing and removal techniques idealized for pipelines, especially the higher technological ones, are not viable in wells due to inaccessibility or disproportionate cost.

This document is a critical review on this flow assurance problem in wells. Its aim is to identify the most recent developments in prevention and removal techniques and investigate which of those have been validated for use in vertical oil wells or are in conditions for being validated in near future.

\section{Methods to identify wax deposits inside wells}

A large-scale wax deposit, or even a complete blockage of any production structure, can easily be detected, considering the associated production decrease. However, detecting smaller or incipient deposits is a stepping stone for assuring flow conditions, production in the long run, avoiding downtime and preventing costly interventions.

For such an end, there are several methods available for measuring the wax thickness on the pipeline's walls. For instance, indirect methods can be employed during the operation process, without downtime (Chen et al. 1997). Among the possibilities, it is worth mentioning pressure drop method, heat transfer method, pressure wave propagation technique to find the blockage location by measuring the time spent by a pressure wave to be reflected back along the pipeline from the point of blockage (Chen et al. 2007) or the use of a calliper and video camera on a remotely operated submersible to measure the (previously pressurized) pipeline diameter.

However, practical methods to predict wax blockages inside the producing wells still need to be improved. Not all the former options are viable solutions for wells. In fact, the most common way for detecting wax deposits in wells is the pressure drop method. It is expected that the process of wax deposition will result in the increase of the pressure drop gradient. The pressure drop along the tubing can be expressed as:

$\Delta P=f \frac{L}{D} \frac{\rho V^{2}}{2}$,

where $\Delta P$ is the pressure drop (Pa), $f$ is the Moody hydraulic friction coefficient (for Newtonian fluid $f=\frac{64}{\mathrm{Re}}$ ), $L$ is the length of the pipe (m), $D$ is the inner diameter $(\mathrm{m}), \rho$ is the fluid density $\left(\mathrm{kg} / \mathrm{m}^{3}\right), V$ is the velocity of fluid $(\mathrm{m} / \mathrm{s})$ and $Q$ is the volumetric flow rate $\left(\mathrm{m}^{3} / \mathrm{s}\right)$.

Considering the ratio between the real and the reference pressure drop, it is possible to estimate the wax layer thickness (Quan et al. 2016):

$\frac{\Delta P_{\text {real }}}{\Delta P_{\text {reference }}}=\frac{f_{\text {real }}}{f_{\text {reference }}} \frac{L_{\text {real }}}{L_{\text {reference }}} \frac{\rho_{\text {real }}}{\rho_{\text {reference }}}\left(\frac{Q_{\text {real }}}{Q_{\text {reference }}}\right)^{2}\left(\frac{D_{\text {reference }}}{D_{\text {real }}}\right)^{5}$.

Assuming the maintenance of fluid properties $\left(\rho_{\text {real }}=\rho_{\text {reference }}\right)$, the ratio is given by:

$\frac{\Delta P_{\text {real }}}{\Delta P_{\text {reference }}}=\frac{f_{\text {real }}}{f_{\text {reference }}}\left(\frac{Q_{\text {real }}}{Q_{\text {reference }}}\right)^{2}\left(\frac{D_{\text {reference }}}{D_{\text {real }}}\right)^{5}$.

Rearranging the equation, it is possible to determine the net diameter:

$D_{\text {real }}=D_{\text {reference }}\left[\frac{f_{\text {real }}}{f_{\text {reference }}}\left(\frac{Q_{\text {real }}}{Q_{\text {reference }}}\right)^{2} \frac{\Delta P_{\text {reference }}}{\Delta P_{\text {real }}}\right]^{1 / 5}$.

The reduction of oil production, from $Q_{\text {reference }}$ to $Q_{\text {real }}$, can indicate the decrease of net tubing area due to wax deposition, when it is accurate to consider stability in the reservoir pressure conditions.

Heat transfer method is used to compare the heat transfer coefficient before and after the appearance of the wax deposit layer.

The total heat transfer resistance is the summation of resistances due to convective heat transfer from bulk fluid to the pipe wall, conduction through the pipe wall and the insulation or coatings materials, and the convective heat transfer to the surroundings, given by Eq. (5):

$\frac{T_{\mathrm{f}}-T_{\mathrm{o}}}{q_{\mathrm{o}}}=\frac{1}{h_{\mathrm{w}}} \frac{r_{\mathrm{o}}}{r_{\mathrm{i}}}+\frac{r_{\mathrm{o}}}{k_{\mathrm{p}}} \ln \frac{r_{\mathrm{o}}}{r_{\mathrm{i}}}+\frac{1}{h_{\mathrm{o}}}$,

where $T_{\mathrm{f}}$ is the bulk fluid temperature in the pipe, $T_{\mathrm{o}}$ is the outside pipe wall temperature, $q_{\mathrm{o}}$ is the heat flux through the outside pipe wall, $r_{\mathrm{o}}$ and $r_{\mathrm{i}}$ are the outside and inside radius of the pipe, $k_{\mathrm{p}}$ are the thermal conductivity the pipe wall, and $h_{\mathrm{o}}$ is the heat transfer coefficient from the outside pipe wall to environment.

After the wax deposit is formed, it is necessary to consider convective heat transfer from the bulk fluid to the paraffin deposit and conduction through this waxy layer, using the heat transfer as shown in Eq. (6):

$\frac{T_{\mathrm{f}}-T_{\mathrm{o}}}{q_{\mathrm{o}}}=\frac{1}{h_{\mathrm{w}}} \frac{r_{\mathrm{o}}}{r_{\mathrm{i}}-\delta_{\mathrm{w}}}+\frac{r_{\mathrm{o}}}{k_{\mathrm{w}}} \ln \frac{r_{\mathrm{i}}}{r_{\mathrm{i}}-\delta_{\mathrm{w}}}+\frac{r_{\mathrm{o}}}{k_{\mathrm{p}}} \ln \frac{r_{\mathrm{o}}}{r_{\mathrm{i}}}$,

where $h_{\mathrm{w}}$ is the heat transfer coefficient from the flowing fluid to the wax layer, $k_{\mathrm{w}}$ is the thermal conductivity of the wax deposit, and, $\delta_{\mathrm{w}}$ is the thickness of the wax layer. 
Pressure wave propagation technique is a transient method that can detect the blockage location and predict the size and the length of the blockage (Adewumi et al. 2003; Vítkovský et al. 2003). The pressure waves that propagate through the pipe are reflected after finding a blockage. The magnitude and time of the reflected pressure wavelet are related to the blockage characteristics (Chen et al. 2007). The blockage severity is determined using Eq. (7):

$1-\frac{A_{\mathrm{B}}}{A}=\frac{2 P_{\mathrm{r}} / P_{\mathrm{i}}}{1+P_{\mathrm{r}} / P_{\mathrm{i}}}$

where $A_{\mathrm{B}}$ and $A$ are the cross-sectional area of the pipe with and without blockage, respectively; $P_{\mathrm{i}}$ is the incident acoustic pressure, and $P_{\mathrm{r}}$ is the reflected pressure from the blockage.

Table 1 presents the main advantages and disadvantages of each wax blockage identification method.

\section{Preventing wax deposition inside wells}

Considering the effects of wax deposition on the productive wells, the technical challenges associated with its detection and the economic constraints imposed by its removal, preventing the phenomenon is preferable than taking corrective actions. Therefore, several methods for inhibiting the deposition process have been studied, most of them widely used for pipelines.

The following lines are deemed to discuss the usage of these methods in wells and its adaptation.

\section{Operational conditions}

The reservoir operational conditions depend on several technical and economic factors. To change one of them, it is necessary to evaluate the advantages and disadvantages of such a decision. For example, increasing the oil production could prevent the wax deposition growth, however, the cost benefit of increasing the pump energy consumption should be evaluated. Despite that, we believe it is still pertinent to illustrate how thermal or hydraulic parameters play a role on wax deposition. To avoid wax precipitation, it is necessary to assure that the flow temperature is above cloud point, as already discussed. If the oil production rate is sufficiently high to guarantee the minimum heat loss from the reservoir to the surface, the oil temperature will be above this onset point and it is expected that the paraffin deposits will not appear. Furthermore, higher rates will help preventing wax adhesion, due to shear action near the tubing surface.

The flowing regime also plays an important role in paraffin deposition. There are evidences suggesting the occurrence of lower maximal wax deposition rates for laminar

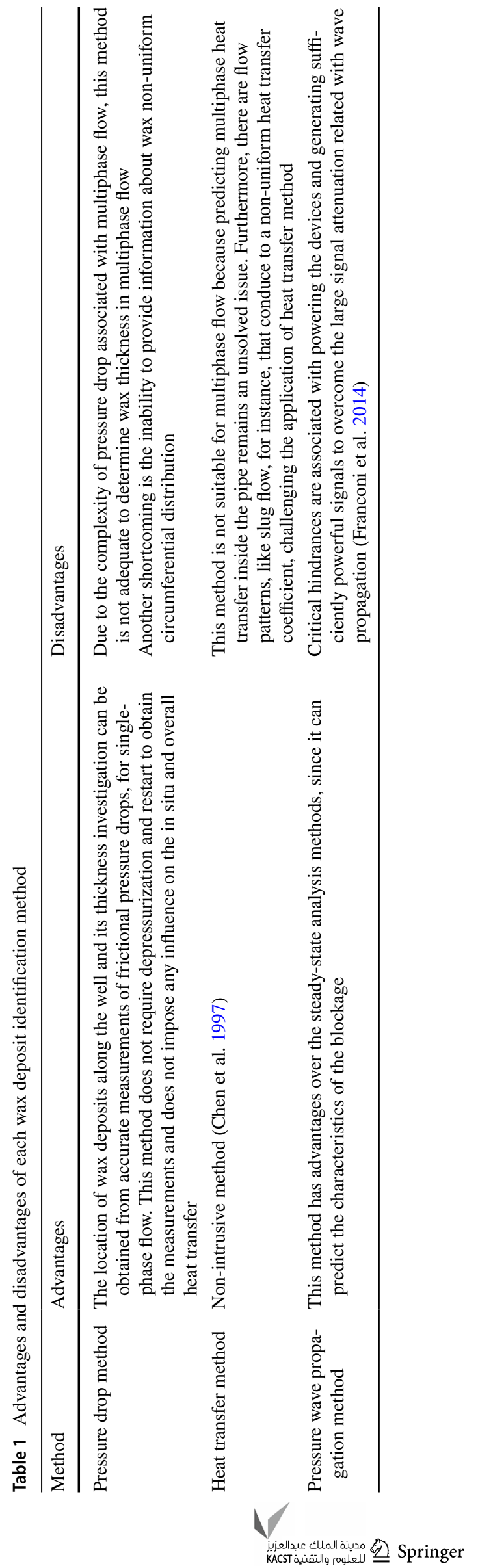


regimes, rather than for turbulent ones, at the beginning of the deposition process. However, for laminar flow regime, the deposit growth rate decreases slower than for the turbulent flow case, so that the deposit layer can ultimately be thicker than for the turbulent case (Sarica and Panacharoensawad 2012).

\section{Wax chemical inhibitors}

For several decades, wax inhibitors, also named as pour point depressants (PPD), wax crystal modifiers or flow improvers, have been used with remarkable success in productive wells (Manka et al. 1999). However, there are many more published papers about wax inhibitors' efficacy in flowlines and pipelines (Jennings and Breitigam 2010; Aiyejina et al. 2011; Chi et al. 2017; Jing et al. 2017; Anisuzzaman et al. 2017) than for wells.

Typically, at site temperature, wax inhibitors are solids. Therefore, to pump it downhole, it is necessary to dilute such particles with solvent. The usage of solvent adds costs and increases the potential hazards.

Wax inhibitors contain crystal modifiers that avoid the formation of large wax molecules by bonding to the wax crystal and impeding further growth. Figure 1 shows a schematic representation of wax crystal modifier co-crystallization with wax crystals.

These polymers need to be added to the crude oil before the wax begins to crystallize. Since inhibitors can only perform effectively for a remarkably narrow range of crude oil compositions (Del García et al. 1998), they must be designed for each crude oil. Likewise, Del García et al. (2001) described a strong relationship between a specific paraffin inhibitor's efficiency and the crude oil composition.

As composition may vary from one well to another, even from the same reservoir, and will also vary over time, periodic sampling and testing are necessary to ensure the chemical's effectiveness.

Manka and Ziegler (2001) and Chen et al. (2010) referred that PPD does not entirely prevent the wax precipitation, but rather shifts its manifestation toward a lower temperature.

Commercially available inhibitors tend to be of limited efficacy. Its adequacy must be evaluated on a case-by-case basis, spanning a wide range of possible effects. For example, while testing some wax inhibitors, Wang et al. (2003) discovered that the analysed inhibitors reduced the total amount of deposition. However, they had limited success in suppressing the deposition of the high molecular weight paraffin components (above $\mathrm{C}_{35}$ ), which leads to harder deposits than in the absence of a wax inhibitor. They also found that the most active inhibitors on depressing the WAT were more likely to be more effective for decreasing total wax deposition. Moreover, the addition of the corrosion inhibitor (oleic imidazoline) significantly increased the efficacy of deposition inhibition.

Studying the efficacy of commercial wax inhibitors on Nigerian crude oils, Bello et al. (2006) found that the use
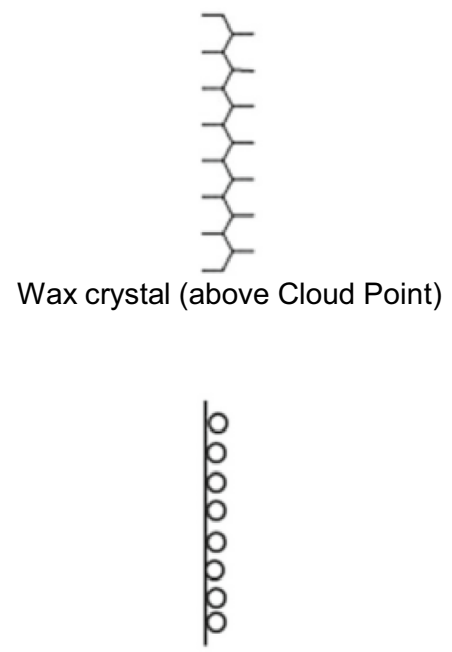

Crystal modifier (CM)

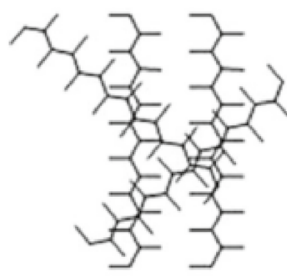

Agglomerating (below Cloud Point)

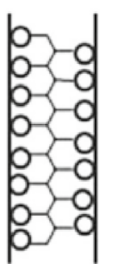

$\mathrm{CM}$ interfering with Agglomeration
Silt, sand, iron oxide particles, entrapped water

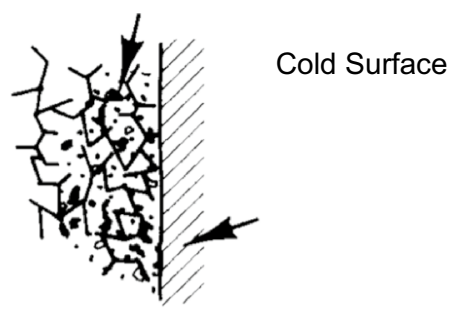

Depositing to the cold surface

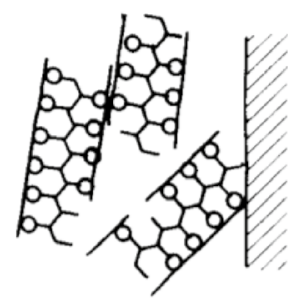

$\mathrm{CM}$ interfering with deposition

Fig. 1 Schematic representation of wax crystal modifier co-crystallization with wax crystals (Allen and Roberts 1978) cited in (Al-Yaari and Fahd 2011) 
of a trichloroethylene-xylene (TEX) binary system, as an additive, was more effective and economically advantageous than using commercial inhibitors.

According to Kelland (2009), the most relevant types of wax inhibitors and PPDs include ethylene polymers and copolymers, comb polymers and assorted other branched polymers with long alkyl groups, such as alkyl phenol-formaldehyde, which are not as effective as comb polymers when acting on their own as flow improvers. Other types of wax inhibitors, such as polyesters and amine ethoxylate detergents or dispersants, may act partly by modifying the surface of the wall, rather than just the wax crystals, to prevent adhesion (Pedersen and Rønningsen 2003), and many effective wax inhibitors create weaker deposits that are more easily removed by shear forces (Manka et al. 1999) and (Kelland 2009).

A comparison between the efficiency of nanohybrid PPD and a traditional ethylene-vinyl acetate copolymer PPD (EVA) was performed by Wang et al. (2011). They concluded that nanohybrid PPDs were more efficient than EVA in reducing the pour point and viscosity.

The search for an efficient PPD led Binks et al. (2015) to investigate how different pour point depressant polymers (HMn-MS-C18-22, LMn-MS-C18-22, LMn-MSAC18-22 e LMn-MSA-C12) affected the pour point transition in mixtures of a single pure wax in a solvent. For such analysis, $n$-eicosane $\left(\mathrm{C}_{20}\right.$ or $\left.\mathrm{CH}_{3}\left(\mathrm{CH}_{2}\right)_{18} \mathrm{CH}_{3}\right)$, $n$-tetracosane $\left(\mathrm{C}_{24}\right.$ or $\left.\mathrm{CH}_{3}\left(\mathrm{CH}_{2}\right)_{22} \mathrm{CH}_{3}\right)$ and $n$-hexatriacontane $\left(\mathrm{C}_{36}\right.$ or $\left.\mathrm{CH}_{3}\left(\mathrm{CH}_{2}\right)_{34} \mathrm{CH}_{3}\right)$ were used as wax component, with either $n$-heptane or toluene as the solvent component. It was noticed that the maximum pour point depression efficacy occurs when the PPD polymer solubility temperature is approximately $15{ }^{\circ} \mathrm{C}$ lower than the wax solubility temperature, in mixtures containing $20 \mathrm{wt} \%$ wax. Therefore, the easiest way to identify the best PPD candidate is to determine the solubility temperature of the PPD.

Yang et al. (2015) studied a novel hybrid PPD, using poly(octadecyl acrylate) (POA) and POA/nanosilica hybrid particles. The addition of this hybrid nanoparticle resulted in free wax crystals with spherical morphology, that avoid the growth of the wax crystals network.

Other strategies have been drawn using certain chemicals' ability to interact with wax deposits. That is the case of the waxophobic nanochemical treatment (Tukenov 2014). This treatment, whose assurance of wax deposition free production was found to last up to 3 months shows some interesting advantages, such as non-toxicity and non-volatilibility.

To understand the influence of the nanohybrid PPDs on flow properties of waxy crude oil, He et al. (2016) performed several experimental analysis. The results demonstrated an improvement in crude oil viscosity, pour point and yield stress, when comparing with the effect of conventional polymers.
To assess chemical inhibitors adequacy to Malaysian crude oil, Ridzuan et al. (2016) compared several inhibitors, namely: poly (ethylene-co-vinyl acetate) (EVA), poly (maleic anhydride-alt-1-octadecene (MA), diethanolamine (DEA), cocamide diethanolamine (C-DEA), toluene, acetone, and cyclohexane. Using the cold finger method and viscosity analysis, the authors sorted out that EVA is the most efficient inhibitor among the pool. Using EVA, the minimum amount of wax deposit and the highest paraffin inhibition efficiency were attained.

Also in 2016, Wei et al. (2016) conveyed a novel wax crystal modifier with "star-like" architecture, based on $\beta$-cyclodextrin. While the results rely only on numerical analyses and laboratory tests, the evidences suggest its ability to significantly reduce the yield stress of a highly waxy oil, as well as, the WAT of the treated oil. Microscopy observations revealed that this wax crystal modifier can efficiently mitigate wax deposition and reduce crystal size. It is also expected that the developed compound can disperse asphaltenes and prevent them from aggregation due to the polar groups such as $-\mathrm{C}=\mathrm{O}$ and $-\mathrm{OH}$.

\section{Coating materials}

By investigating the mechanisms by which waxes adhere to the walls, it is possible to sort out which materials make adhesion unfavourable. The usage of coating materials prevents the precipitated waxes from adhering to the tubing frontier surfaces. Such coating materials are wax-repellent surfaces and, depending on its effectiveness, can greatly reduce the use of inhibitors or the frequency of mechanical removal.

To design wax-preventing coatings, the operational borehole conditions should be considered. The coating material should be resistant to multiphase flow (oil, water, gas, sand) and the flowing simulation must consider the material friction coefficient and the diminution of the inner diameter due to the increment of the coating surface.

Furthermore, to endure long-term operability, the coating material should also be chemically inert, anti-abrasive, anti-corrosive and resistant to other deposits namely: waxes, resins, asphaltenes and scales.

To reduce the effect of wax deposits, successful tests were carried out with hollow rods glass coated on the inside, in the Soviet Union. It was possible to observe a reduction of wax deposits using glass (Szilas 1975).

To share the experience about using glass-reinforced epoxy resin (GRE) tubing in a real production field located at Oman, Archibald and Bulstra (1981) published the results of using this coating material in two water injectors and one gas-lifted oil producer. The two water injectors' tubes had satisfactory behaviour, however, the gas-lifted oil producer 
tubing failed. Three potential causes may have led to its failure: fatigue, over torque or the wireline operations.

Li et al. (1997) studied the wax prevention mechanisms using a glass inner layer inside a pipeline. When the water content was higher than $60 \%$, they observed that the wax deposited on the wall of the glass tube was reduced. On the contrary, for higher water content, when the water flowed as plug flow, the wax deposited on the wall of the glass tube was higher than in steel.

Paso et al. (2009) performed a comprehensive review of the use of non-stick and anti-adhesive coatings for inhibiting solid-liquid deposition phenomena, including metal surface treatments and synthesized polymers. Most meaningful results have been achieved with fluoro-siloxanes, fluoro-urethanes, oxazolane-based polymers, and hybrid diamonds like carbon and polymer coatings.

Zhang et al. (2002), Guo et al. (2012) and Wang et al. (2013) studied the influence of different chemical conversion coatings on wax deposition. These coatings, with a special liquid wettability and non-wax stick properties, have hydrophilic and super-oleophobic properties in a water-oil mixture.

Recently, Liang et al. (2016) studied Zn-coated A3 carbon steel immersed in a phytic acid $\left(\mathrm{C}_{6} \mathrm{H}_{18} \mathrm{O}_{24} \mathrm{P}_{6}\right)$ solution. The prepared coatings had special wetting behaviours of super hydrophilicity and underwater superoleophobicity. The wax deposition tests, along with the calculations performed with the water film theory, suggest a very good behaviour for preventing wax depositions for this environmentally friendly solution.

\section{Insulators' (heat-proofing) materials}

When wax deposition prevention depends on keeping the flow temperature above one certain threshold, either with or without downhole heating, insulating the tubing becomes a necessity. One particular case occurs when insulation materials are installed in contact with the flow. In such cases, the selected material can provide insulation and coating, yielding a double action against wax deposition.

A wide range of organic and inorganic materials are available for thermal insulation. However, only a few are suited for application in wells, considering mechanical and chemical resistance requirements, significant access, installation and maintenance limitations and cost effectiveness, considering the great lengths involved.

Since the thermal insulation goal is to reduce heat transfer between inside and outside, the fundamental material requirement is a low thermal conductivity (Bahadori 2014). In these circumstances, plastic materials are the most adequate. Among those, polyurethane and isocyanurate are commonly used (Bahadori 2014). Nevertheless, chemical industries are continuously providing solutions with increased efficiency and cost effectiveness, such as ethylene tetrafluoroethylene (ETFE) plastic pipe coating (Bagdat and Masoud 2015).

Within the specific case of downhole insulation, vacuuminsulated tubing (VIT) has been the favoured option (Lively 2002). Despite its excellent thermal behaviour, its cost remains a concern. Thus, some variants, such as VIT with appropriate polyurethane coupling insulation, have been investigated (Singh et al. 2007) showing good results and economic viability for the coldest environments.

\section{Heating techniques to prevent wax deposition}

Due to oil expansion from the reservoir to the surface and the heat dissipation along the well, the temperature of the oil decreases. Preventive procedures to avoid wax deposition include improved heat retention using active heating such as the use of electrical heating devices inside the well (Bosh and Eastlund 1992). The energy provided by an electrical heater will keep the oil temperature sufficiently high to prevent paraffin crystallization and the subsequent deposition. Furthermore, by heating the crude, the viscosity will decrease, improving the fluid flowability and possibly conducing to higher pumping rates.

Danilović et al. (2010) studied the use of heating cables for solving paraffin deposition problems in wells' upper tubing. With remarkable success and easy installation, this solution was able to solve the deposits by heating, while increasing the flow, by reducing oil viscosity. Figure 2 shows how the heating cable is helically placed around the tubing.

Electric bottom-hole heaters are designed to deliver controlled amounts of heat energy using externally controlled power cables. Figure 3 shows a schematic representation of a bottom-hole heater.

Although electric bottom-hole heaters offer several operating advantages that could not be obtained with other heating methods, some serious disadvantages have been experienced in site conditions. For example, the power cables, when facing the severe conditions encountered in the wells, show lack of resistance or the deterioration of the rubber insulation, posing serious concerns about this

Fig. 2 Heating cable into the well. Adapted from (Danilović et al. 2010) 


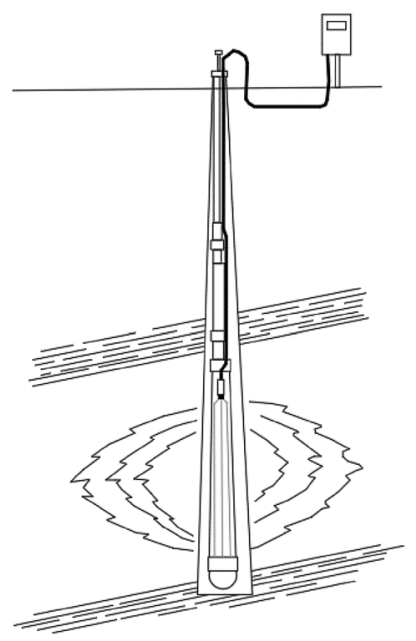

Fig. 3 Example of an electric bottom-hole heater

method. Furthermore, there are records of mechanical failures during the operation (Guerreiro et al. 2012). Electrical heaters frequently burn out, so it is prudent to use an automatic switch to shut off the current when the heater becomes overheated.

Recent numerical investigations have been developed to calculate the heat required for an electrical cable, Kovrigin and Kukharchuk studied an automatic control system considering the minimum heat necessary to melt the waxes and simultaneously guaranteeing that the temperature would not surpass the maximum operating temperature of the cable insulation (Kovrigin and Kukharchuk 2016).

\section{Cold flow}

One interesting thermal method for inhibiting wax deposition, other than heating, is the cold flow technology (MerinoGarcia and Correra 2008). This technique is deemed to prevent deposition on the flow frontiers by reducing the bulk temperature within the flow to be equal to the temperature of such frontiers around it, thus eliminating the temperature gradient. Therefore, the waxes are transported as a solid particle suspension within the bulk fluid. While wax deposition may be avoided by eliminating the heat flux, even below the WAT, much work is still needed to develop the technology required for effectively cooling the bulk fluid to this condition and for transporting the resulting cold slurry over long distances. Additionally, Haghighi et al. (2007) and Azarinezhad et al. (2010) proposed a wet cold flow-based concept with the potential benefit of wax inhibition.

It is important to observe, though, that geothermal gradient along long wells is a severe constraint for creating the thermal conditions necessary to materialize a cold flow technology realization (Fig. 4).

\section{Acoustic methods}

Acoustic (or sonic) methods have recently gained wide employment within the enhanced oil recovery context. Recent research (Hou et al. 2015) reports findings on several mechanisms introduced by acoustic mechanisms, namely the influence of acoustic waves on oil fluidity, pressure gradient and interfacial tension of capillary in the reservoir, as well as the acoustic impact-induced fluctuations on oil reservoir pressure.

Furthermore, recent applications in existing wells in the Russian Federation and the United States of America found stimulation methods by radiating systems of downhole tools that proved to be very effective for oil recovery (Mullakaev et al. 2015) (Fig. 5).

Acoustic methods have been studied in the past decades and its effects are already well-known (Hamida 2007). Ultrasonic irradiation has proven to be an effective tool to stimulate multiphase flow through porous media, even though acoustic interaction between fluid and rock still requires further studies. Among the mechanisms usually referred for enhancing the flow of oil through porous media in the presence of an acoustic field, capillary effects and several
Fig. 4 Schematic representation of a cold flow system

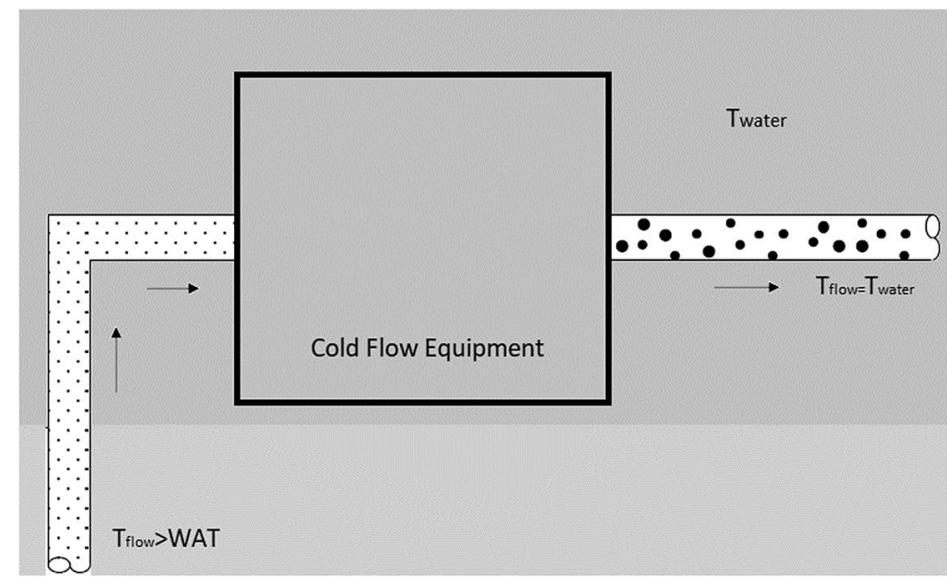

Dissolved Wax Precipitated Wax 
Fig. 5 Treatment of the nearwellbore area by the downhole tool PSMS-102. Adapted from (Mullakaev et al. 2015)

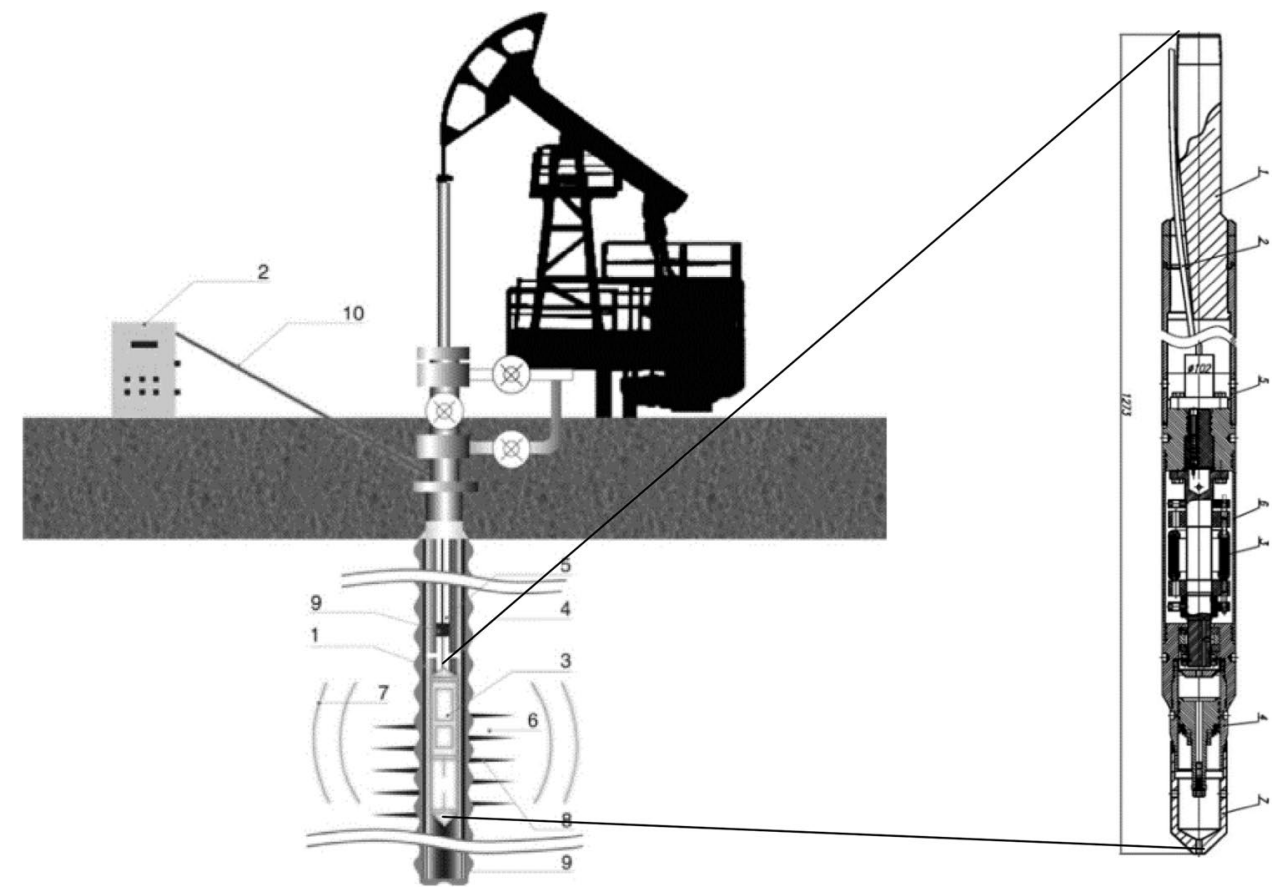

forces originated in motion can also play a key role in wax deposition prevention.

Such approach has long been proposed by Roberts et al. (1996). Their reported experiments proved the capacity of cleaning precipitated paraffin deposits inside the rock pore space matrix using acoustic energy, since exposure of such deposits to direct acoustic radiation favoured its easy removal.

Nevertheless, consulting the available bibliography, practical and effective means to apply these principia to wells in an extensive manner have not been found yet.

\section{Wax inhibiting tool (WIT)}

To mitigate wax deposition problems in Niger Delta explorations, the use of metallic equipment has been reported. Such solution, usually referred to as wax inhibiting tool (WIT) is a device made in alloys that can change crude oil properties, while it flows through them.

A Silver-Hawg WIT has been assessed by Sulaimon et al. (2010). Albeit the equipment proven functionality, whose crude oil modification implies keeping paraffin and other waxes in suspension, as well as breaking up long chains of hydrocarbon molecules, the practical results have shown some shortcomings. In fact, the tubular tool fulfilled its purpose in a limited number of applications, leading to the conclusion that its position inside the production tubing or along the flow line requires further studies. Indeed, the aforementioned studies found that the tool works properly only when installed at the wax nucleation depth.
Shortly after, Sulaiman et al. developed a Piezoelectric WIT using semi-precious metals and quartz (Sulaiman et al. 2011). Zinc and lead were mixed with quartz and, subsequently used to fabricate the tool with an aluminium matrix. Site testing in a flow line was able to provide encouraging results, as the thickness of the assessed deposits reduced significantly (over 32\%).

Another inhibiting tool, that applies passive energy to the fluid, was studied by Hamilton and Herman (2011). Field experience, using this device inside the wells, did show an improvement in the gross fluid production and a reduction of pumping frequency.

\section{Electric field}

Considering the difficulties reported in using heating methods and drag-reducing agents, namely high-energy consumption and environmental impacts in the former and high costs and lack of efficiency for laminar flows in the latter, further methods have been developed. Thus, from 2006 on, several electrorheology applications have been reported. After several developments, Tao and Tang proposed imposing a strong local electric field which is able to polarize oil-suspended particles, in pipelines (Tao and Tang 2014). Induced dipolar interaction forces aggregate particles into short chains and, therefore, decrease crude oil viscosity.

The aforementioned study found the method to be effective for several types of crude oil, including asphalt base crude oil and paraffin base crude oil. Its effect is almost instantaneous and lasts for more than $11 \mathrm{~h}$, along which viscosity is significantly lower and flow rate can increase up 
to double. One very interesting advantage is the low energy consumption.

Recently, other methods involving the use of electric fields have been proposed. For instance, Krasnov et al. (2017) suggested employing electric current throughout pipelines or downhole equipment to create cathode polarization. For attaining this, two methods are possible. Those methods are either the imposition of an external source of current or artificial creation of galvanic elements. With this technique, several effects are pursued, namely the decrease of adhesion among crude oil particles, local heating and creation of an electrostatic field, whose polarity avoids particles' deposition.

\section{Magnetic field}

According to Gonçalves et al. experiments, a magnetic field was found having an impact on the paraffin crystal formation, since it avoided the formation of paraffin cluster (Gonçalves et al. 2010). They found out that under a $0.3 \mathrm{~T}$ magnetic field, the crystallization was lower than that without the effect of a magnetic field. However, they also found that rheological changes in crude oil due to magnetic fields exposure is strongly dependent on the crude constitution (Gonçalves et al. 2011).

Previously, Tao et al. had also noticed that applying a magnetic field could reduce the crude viscosity. Their experiments shown that a paraffin base crude oil could have its viscosity reduced for several hours. Using a magnetic field will not act upon the oil temperature but will temporary aggregate paraffin particles into the crude oil (Tao and Xu 2006). Subsequently, a viscosity reduction is expected.

It is important to observe that the experiments, that substantiate the former results, have been derived from small laboratory apparatus or short pipelines. Thus, the results' applicability and the technology adequacy applied to wells require further studies.

\section{Oscillatory motion}

Oscillatory motion has been proposed as a method for wax deposition avoidance and removal. Such hypothesis can be theoretically sustained through Avrami theory (Ismail et al. 2008), but its practical application has not been proven yet. To investigate its practical effectiveness, the aforementioned researchers performed laboratory experiments.

The attained results are interesting but are far from granting feasibility to the technology. In fact, oscillatory motion was able to significantly reduce the wax deposition (40-60\%) and completely prevent wax gelation from occurring, provided the wax content is low. However, at higher wax contents, the results were contrary. Oscillation accelerated crystal growth so that total wax deposition was even achieved.

In this manner, beyond being a difficult technology to implement, the uncertainty in crude oil contents may hinder putting this method to practice.

\section{Wax removal techniques}

Either when wax deposition cannot be prevented or when the employed prevention techniques do not offer a fully effective solution, removal techniques become necessary to avoid production decrease or, even, total blockage.

Among several methods developed mostly for pipelines, a few can be used in wells, namely mechanical removal methods, fused chemical exothermic reactions and wax-removing chemicals (paraffin solvents and dispersants). To these options, one can add bottom-hole heaters, which have been developed solely for wells.

To discover more efficient and cost-effective removing techniques, several investigations have been carried out. Below, a critical review of such methods is presented.

\section{Mechanical removal}

The most straightforward, antique and widely used technique for solving wax problems inside wells is mechanical removal (Irwin 1955). It is common to let the paraffin accumulate inside the flowing wells, until a certain amount, and then remove it using mechanical devices. In oil wells, usually, scrapers and cutters are used to remove paraffinic deposits (Al-Yaari and Fahd 2011). There are generally two types of tools: one that cuts the deposit from the tubing and allow the producing oil to bring it to the surface, and another one that scraps and removes the deposit from the tubing. Figure 6 shows an example of a schematic wax cutter used to cut deposits from the casing (left) and from the tubing (right), without interfering with the production.

Figure 7 shows an example of a schematic wax hook used to scrape and remove wax deposits from the casing (left) and from the tubing (right).

During this procedure, the cutting tool or the scraper scratches the tubing wall due to the metal-to-metal contact. This roughness promotes wax deposition, as it has been proven that paraffin deposits tend to adhere to roughened surfaces rather than polished metal surfaces.

Scrapping physically removes paraffin without melting it. This procedure includes launching the equipment along the pipe to scrape paraffin deposits from the walls. However, this could lead to the risk of forming a wax plug as the scraped wax accumulates.

If paraffin deposits are very hard, mechanical removal can be supplemented by a chemical soak.

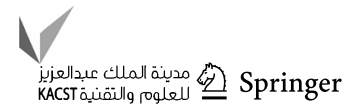



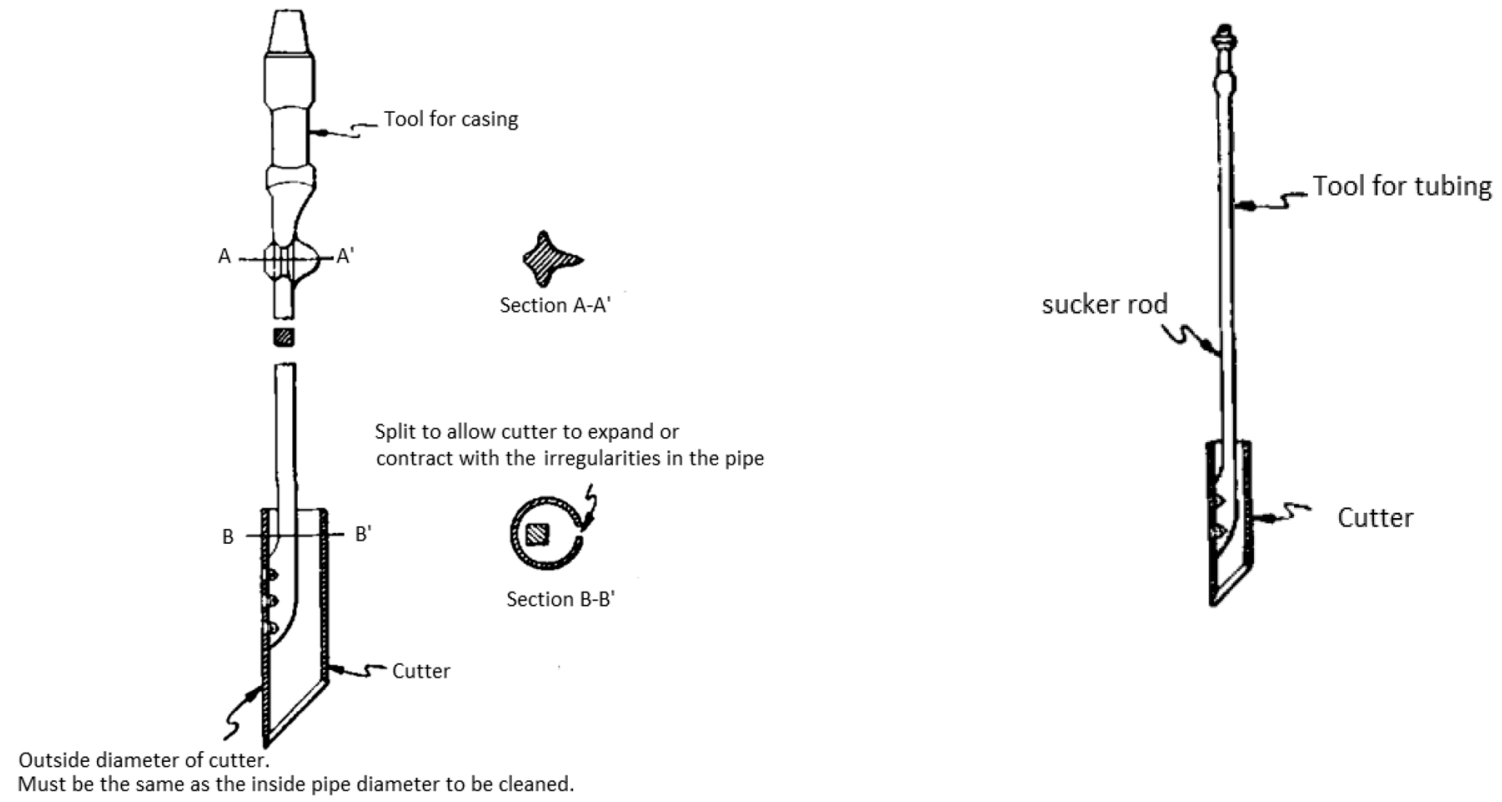

Must be the same as the inside pipe diameter to be cleaned.

Fig. 6 Schematic representation of a wax cutting tool. Adapted from (Reistle and Blade 1932)

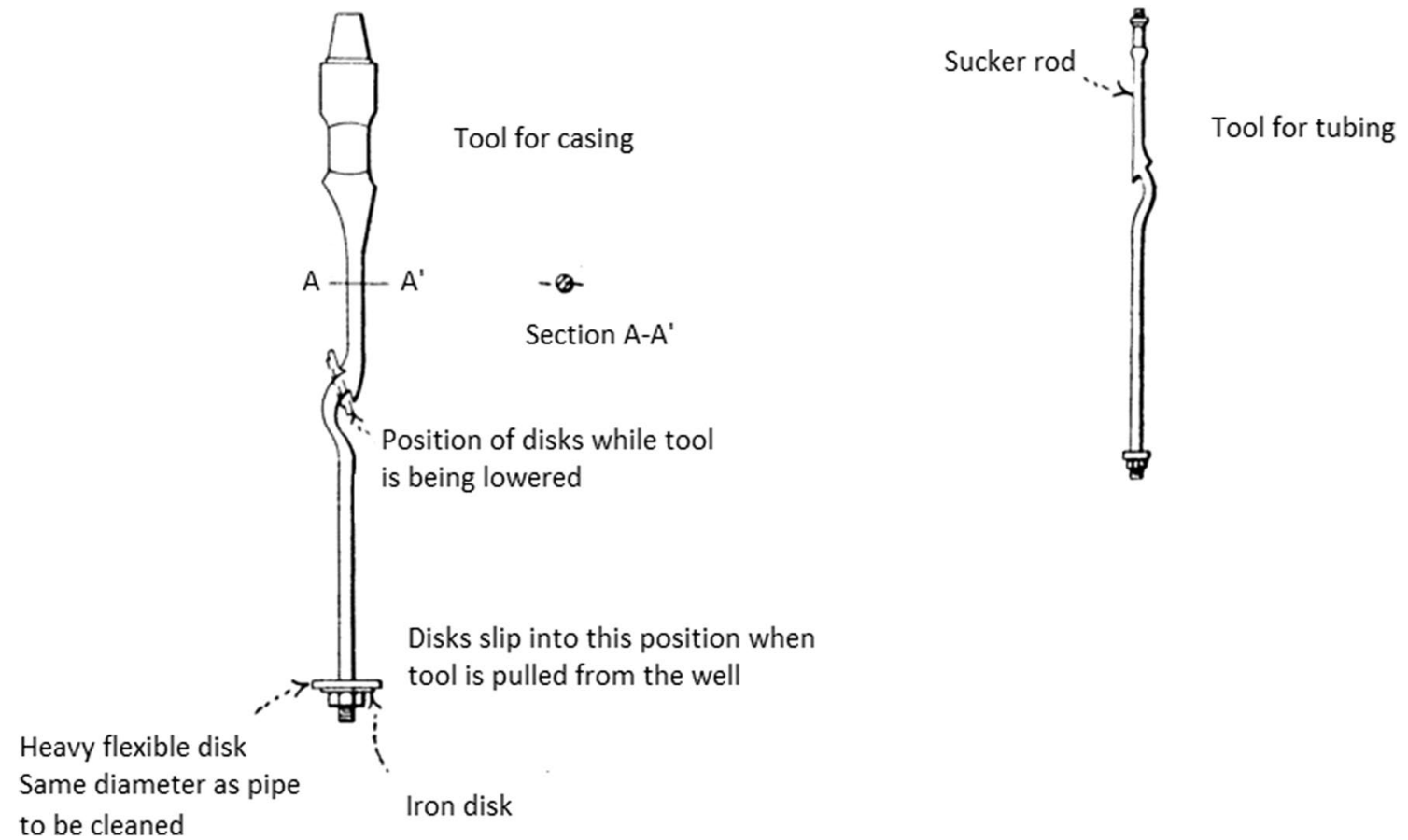

Fig. 7 Example of a wax hook tool. Adapted from (Reistle and Blade 1932)

In pumped wells, when the wax deposition grows the load on the rods increases. If the deposits are not removed, the load becomes so excessive that the rod breaks. Furthermore, the existence of tough waxes also hinders while pulling the broken rods.
If the producing well has a downhole centrifugal pump, a common option is to use a scraper attached to a wireline. Nevertheless, this procedure may be counterproductive, since during these operations, the wireline may break, and 
the scraper will be stuck inside the well (Al-Yaari and Fahd 2011).

If the paraffin problems are extensive and require frequent mechanical removal operations, this procedure may become costly. Additionally, for isolated wells, the minimum charges can also be expensive. Generally, this procedure is used when hot oiling cannot be used (Khandekar 2015). However, mechanical removal is not so efficient as hot oiling, being about 67\% effective (Khandekar 2015).

\section{Chemicals}

Two types of chemicals are commonly used for removing wax depositions: the first generates heat as a result of an exothermal chemical reaction, which occurs in the well when it is mixed with other specific chemicals or water; the second group of chemicals includes the solvents and dispersants that need to be added continuously to treat the oil.

\section{Chemical exothermal reactions}

Using chemicals to remove wax deposition from the tubing is very unlikely, due to the difficulty of causing an exothermal chemical reaction in the right location, to melt the wax deposition inside the tubing. In fact, if this reaction occurs in the bottom of the well, the heat will probably dissipate before achieving the paraffin accumulation. To assure the occurrence of the melting process, a large quantity of chemicals needs to be used, which makes this method economically non-viable.

Considering this, Ashton et al. performed experiments with a delayed reaction chemical compound based on $\mathrm{NH}_{4} \mathrm{Cl}$ and $\mathrm{NaNO}_{2}$ (Ashton et al. 1989). With it, they were able to heat a region around the wellbore, as well as on lowpermeability sections of the formation. The extent of the heated zone depended on the volume of pumped chemicals. Despite the functional improvements, practical application and cost effectiveness of the method remain an obstacle for its widespread use. Nevertheless, some applications have been found, such as the one documented by Tiwari et al. in Indian oilfields (Tiwari et al. 2014).

They reportedly used the following exothermic reaction in one successful trial after laboratory testing, using sodium nitrite $\left(\mathrm{NaNO}_{2}\right)$, ammonium chloride $\left(\mathrm{NH}_{4} \mathrm{Cl}\right)$ and attaining sodium chloride $(\mathrm{NaCl})$ :

$\mathrm{NaNO}_{2}+\mathrm{NH}_{4} \mathrm{Cl} \rightarrow \mathrm{NaCl}+\mathrm{N}_{2}+2 \mathrm{H}_{2} \mathrm{O}$.

Exothermal reactions can, either, be mixed with other effects to compose more robust dewaxing thermo-chemical packages. One example is the nitrogen generating system, pioneered by Petrobras in 1992 (Thota and Onyeanuna 2016). Beyond the exothermal effect, the ammonium chloride and sodium nitrite package count with its effervescent reaction to remove wax deposits. Albeit it was used for a long time, this technology also showed the shortcoming of offering a solution that is very constrained in space, to the point where the chemicals are injected. Considering this, Halliburton developed in 2012, a similar package with a delayed effect, the SureTherm (Thota and Onyeanuna 2016). Its trials in West Africa have reportedly been successful.

\section{Chemical solvents and dispersants}

Two types of chemicals can be used to remediate wax deposition: solvents and dispersants. While the first is used to dissolve the paraffin deposits, dispersants are responsible for breaking up the wax particles so that the production flow carries it.

Using gasoline, kerosene or benzol as chemical solvent is possibly the oldest method to remove wax deposited inside the wells. To remove wax deposits, gasoline is considerably a better solvent than kerosene. The suitability of using solvents to remove waxes depends upon the solvent cost. However, as the solvent is also recovered as crude oil, the added value should be deduced from the solvent gross cost.

This method can be applied in pumping wells, but it can hardly ever be used in natural flowing wells, since it is hard to inject liquid solvents into the flowing wells.

Straub et al. tested several solvents (xylene, kerosene, diesel, condensate, oil, toluene, gasoline, and mixtures of the products) to access which one could reliably dissolve paraffinic deposits, for a wide range of wells (Straub et al. 1989). It was proven that xylene or xylene mixtures dissolved the paraffin faster than the other solvents, for $82 \%$ of the tests. They concluded that the solvent reaction is mainly influenced by the solvent type, paraffin characteristics, and temperature.

According to Al-Yaari and Fahd, carbon tetrachloride and carbon disulphide have been used as the universal solvent (Al-Yaari and Fahd 2011). Kerosene, condensate and diesel oil are used too, as solvents, to dissolve the low asphaltene content in paraffin deposits.

El-Gamal et al. synthesized nitrogen-based one component polymeric structures that exhibit dual function: wax dispersants and flow improvers. They determined that the dispersing effect is dependent on the polar effect of nitrogen/oxygen. It is also mentioned that their effectiveness is a function of permeability inside the paraffin wax crystals' formation (El-Gamal et al. 1998).

\section{Heating techniques to remove the wax deposits}

The main purpose of this solution is to supply heat to the producing wells to melt and dissolve the deposited paraffin, so that it can be transported with the oil to the surface. However, when heating the produced oil, special attention

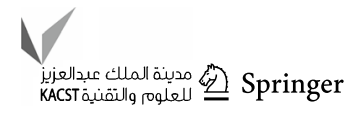


should be given to guarantee that the oil temperature will not rise too much, otherwise the crude may coke and plug the wellbore.

Besides the usage of bottom-hole heaters, other heating methods are used to remove wax deposits, namely: hot oil circulation and hot water circulation. The first one consists of heating a portion of the produced oil and returning it into the well. During the oil heating process, the lighter components will evaporate, and the commercial value of the oil produced during the dewaxing operation will be lower. When hot oil flows between the tubing and the casing, it loses its internal heat to the outside surrounding areas. If this high paraffinic hot oil reaches the bottom hole with a temperature below WAT, wax deposition can occur. Furthermore, the crude oil can contain other solids like iron sulphide, clay, sand or iron oxide that can also deposit.

The concept of using hot watering is like hot oiling, and this method is used as an alternative to it. Water contains a higher heat capacity than the oil, for the same temperature, making it an interesting solution and cost effective. The other advantage of hot water is that water does not contain contaminants that may be present in oil (Khandekar 2015). However, hot water cannot provide the solvency available in hot oiling. Furthermore, surfactants need to be added to help the dispersion of wax into the water phase. To be effective, the surfactant needs to be in contact with melted paraffin, otherwise the mixture of water and surfactant will produce very large water-wet particles of wax. To demulsify the water-wet waxes solution, greater amounts of demulsifier needs to be used than usually used in the two-phase water and oil.

Injecting steam into the space between the tubing and the casing is another heating technique used to dissolve the paraffinic waxes. The steam should be applied to a depth below the lowest point of accumulation, to heat the crude oil between 55 and $65^{\circ} \mathrm{C}$. Moreover, the amount of heat and the duration required will depend upon the well conditions and this can only be determined by testing in site. Nevertheless, it is common to leave the steam produce effect for 3-6 h.

To apply this method, the available steam pressure must be higher than the formation pressure. Furthermore, it is necessary to guarantee that the condensate steam will not damage the formation or emulsify with the oil, causing emulsion troubles.

The steam injection is a suitable method to remove wax deposits. However, to apply this procedure, it is necessary to stop the production while the wax is being removed. If the production does not begin immediately after the valve is open, after the steaming, the melted wax will accumulate and settle below the valve.

The usage of steam is not as economical or practical, as using a scraper. However, in some oil fields where the steam is available without extra expenses, this method must be used.

Recently, Zyrin proposed the use of an electrical heating device on the well bottom zone, adjoined with electrical steam generator (Zyrin 2016).

None of these measures is seen to be effective in the long term to prevent wax deposition in the field cases. For instance, Straub et al. denoted that hot oiling treatments performed did not produce permanent advantages (Straub et al. 1989).

\section{Bacterial treatment}

Biological wax removal methods have been thoroughly investigated in recent years by several researchers. The results attained by Rana et al. showed that the developed bacterial systems of paraffin-degrading bacteria with nutrient supplements and growth enhancers could eliminate the need for repeated scrapings of wax over a period of several months (Rana et al. 2010). If successfully implemented, these methods have the benefit of providing continuous control of wax deposition through constant biodegradation, instead of just providing a temporary solution.

Etoumi et al evaluated the use of Pseudomonas bacteria for the reduction of wax precipitation in waxy crude oils (Etoumi et al. 2008). They concluded that Pseudomonas species can emulsify immiscible hydrocarbons such as kerosene, toluene, xylene and crude oil. Other researchers, such as Sifour et al. corroborate this conclusion (Sifour et al. 2007). Pseudomonas treatment on crude oil was shown to be effective in reducing the concentration of long-chain hydrocarbons $\left(\mathrm{C}_{22}+\right)$. Furthermore, Etoumi et al. concluded that Pseudomonas species are able to reduce paraffin deposition, and that the speed of the biochemical action on crude oil is faster within the first 7 days. They also observed a reduction in viscosity and WAT which is indicative of the conversion of long-chain alkenes to short ones (Etoumi et al. 2008). Also, Sood and Lal studied the paraffin degradation of crude oil by a thermophilic, paraffin-degrading, bacterial strain (Sood and Lal 2008).

Within the laboratory domain, Xiao et al. used two microbial strains to remove paraffin deposits on stainless steel surfaces (Xiao et al. 2012). Those were Pseudomonas Aeruginosa (N2) and Bacillus Licheniformis (KB18). They were able to draw the conclusion that biosurfactant-producing species can change the wettability of stainless steel to water wet and reduce the adhesion of the aqueous phase to the stainless steel by forming an emulsion. This mechanism may be of paramount importance to preventing the paraffin deposition. These studies reached very promising results in what concerns the process efficiency. In fact, the paraffin removal efficiency accomplished by bacterial treatment could reach $79.0 \%$. Previously, Lazar et al. composed 


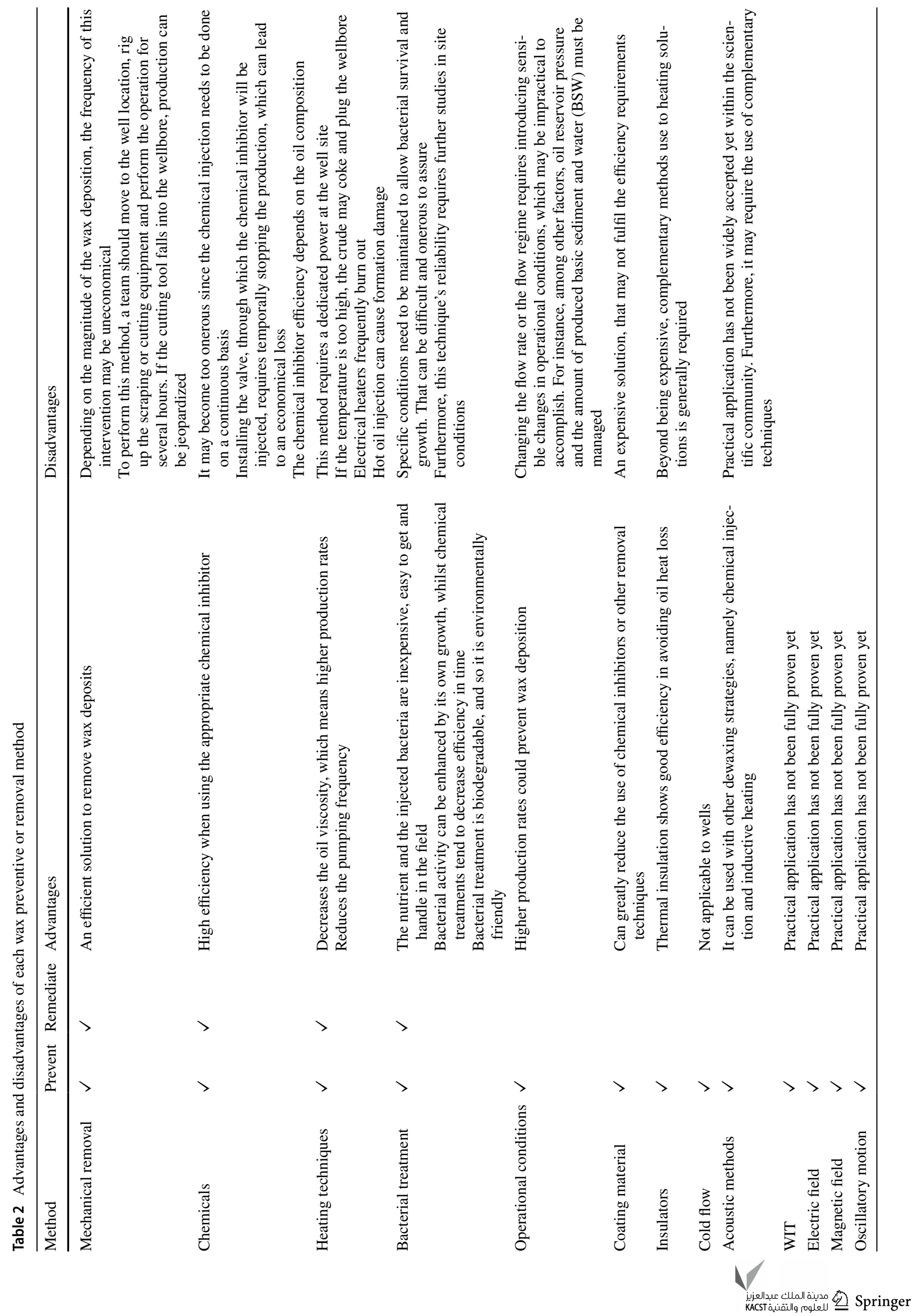


Fig. 8 Decision tree to choose the wax deposition preventing or removal technique

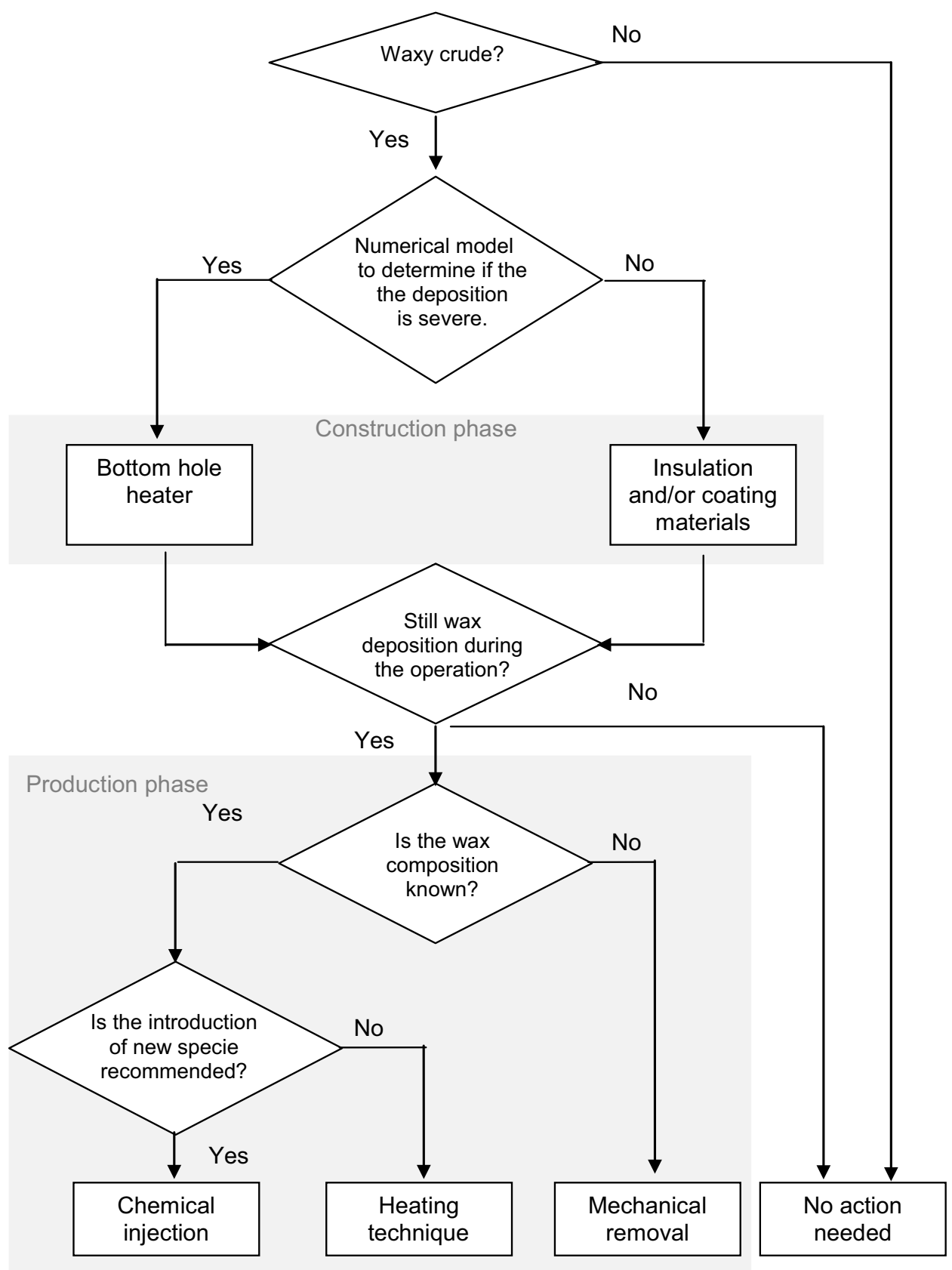

a special bacterial consortium, by isolating and selecting naturally occurring bacterial strains and bacterial consortia from waste hydrocarbon-contaminated sites, with which they were able to remove solid and semi-solid paraffin depositions on flow equipment (Lazar et al. 1999).

Beyond the laboratory and piping domains, the research undertaken in field and test wells is extremely important, once it provides sensible information on the applicability of bacterial treatments in real conditions and in large scale.

Despite the scarce availability of results in those conditions, it is important to highlight the work of He et al. since they identified, through field tests, two Bacillus species and a Pseudomonas species that showed good paraffin removal properties in test wells (He et al. 2003). Using those, it was shown possible to increase oil production and eliminate the need for more expensive wax removal processes.

Moreover, Xiao et al. were able to mitigate paraffin deposition through the injection of a biological solution in oil wells during a pilot test (Xiao et al. 2012). As a result, most of the treated wells flowed for 6-8 months without any wax deposition. In addition, the average period of effectiveness for the surface flow lines was 4-5 months after treatment.

Previously, Santamaria and George had studied the use of commercially available bacteria on five wells with paraffin 
deposition problems (Santamaria and George 1991). In severely affected five wells, they were able to reduce the periodicity of heavy maintenance production interruptions, from twice a week or twice a month to once every 6 months by pouring paraffin-treating bacteria. Despite not having reported adverse effects in produced water from the wells, nor the increase in corrosion problems, those could not be definitively ruled out. Furthermore, those specific bacteria have its use limited to water-producing wells, with bottomhole temperatures not exceeding $100{ }^{\circ} \mathrm{C}$.

\section{Conclusions}

Currently, the technical solution of most widespread use for removing wax deposits in vertical oil wells is mechanical removal. Considering both the classic approaches and the most recent state-of-the-art technologies, it is reasonable to foresee that in future, significant developments and practical applications will occur concerning the remaining technologies, namely the development of new chemical inhibitors, innovative heating devices and effective bacterial treatments that could be injected in wells.

For each wax preventive or removal method discussed, a critical review spanning their main advantages and disadvantages can be found in Table 2 .

As a final remark, it is important to stress out that any sensible evolution within the prevention and removal techniques will necessarily require advances in the wax deposition modelling, to enhance its adequacy and efficiency.

To decide which technique should be used to prevent or remediate the wax deposition, a decision tree is presented in Fig. 8, showing only the most used techniques.

Acknowledgements The authors would like to thank to Partex Oil and Gas for the technical and financial support, through the Grant UID/ECI/04028/2013 (from September 2017 until March 2018) and Fundação para a Ciência e a Tecnologia, I. P, for the financial support, through the Grant SFRH/BD/131005/2017 (from April 2018).

\section{Compliance with ethical standards}

Conflict of interest Authors have no other competing interests to declare.

Open Access This article is distributed under the terms of the Creative Commons Attribution 4.0 International License (http://creativeco mmons.org/licenses/by/4.0/), which permits unrestricted use, distribution, and reproduction in any medium, provided you give appropriate credit to the original author(s) and the source, provide a link to the Creative Commons license, and indicate if changes were made.

\section{References}

Adewumi MA, Eltohami ES, Solaja A (2003) Possible detection of multiple blockages using transients. J Energy Resour. Technol [Internet] 125(2):154. http://energyresources.asmedigitalcollectio n.asme.org/article.aspx?articleid $=1414232$

Aiyejina A, Chakrabarti DP, Pilgrim A, Sastry MKS (2011) Wax formation in oil pipelines: a critical review. Int J Multiph Flow 37:671-694

Allen TO, Roberts AP (1978) Production operations 2. Well completions, workover, and simulation, 3rd edn. Oil \& Gas Consultants International, Inc, Tulsa

Al-Yaari M, Fahd K (2011) Paraffin wax deposition: mitigation and removal techniques. SPE Int 155412(March):14-16

Anisuzzaman SM, Abang S, Bono A, Krishnaiah D, Ismail NM, Sandrison GB (2017) An evaluation of solubility of wax and asphaltene in crude oil for improved flow properties using a copolymer solubilized in organic solvent with an aromatic hydrocarbon. World Acad Sci Eng Technol Int Sci Index Bioeng Life Sci 11(10):688-695

Archibald RM, Bulstra RA (1981) Use of glass reinforced epoxy resin tubing in Oman. Middle east tech conf and Exibition (9-12 March, Bahrain), SPE [Internet], pp 565-572. https://doi. org/10.2118/9636-MS

Ashton JP, Kirspel LJ, Nguyen HT, Credeur DJ (1989) In situ heat system stimulates paraffinic-crude producers in Gulf of Mexico. SPE Prod Eng 4:157-160

Azarinezhad R, Chapoy A, Anderson R, Tohidi B (2010) A wet cold-flow technology for tackling offshore flow-assurance problems. SPE Proj Facil Constr [Internet] 5(02):58-64. https://doi. org/10.2118/132349-PA

Bagdat M, Masoud R (2015) Control of paraffin deposition in production operation by using ethylene-tetrafluoroethylene (ETFE). In: Proc. Int. Conf. Integr. Pet. Eng. Geosci. Icipeg 2014 [Internet], pp 13-22. https://doi.org/10.1007/978-981-287-368-2. http:// www.springer.com/978-981-287-367-5

Bahadori A (2014) Design and application of thermal insulation. In: Thermal insulation handbook for Oil, Gas, Petrochemical Industries, 1st edition, Elsevier Inc., ISBN 9780128000106

Banki R, Hoteit H, Firoozabadi A (2008) Mathematical formulation and numerical modeling of wax deposition in pipelines from enthalpy-porosity approach and irreversible thermodynamics. Int J Heat Mass Transf 51(13-14):3387-3398

Bello OO, Fasesan SO, Teodoriu C, Reinicke KM (2006) An evaluation of the performance of selected wax inhibitors on paraffin deposition of Nigerian crude oils. Pet Sci Technol 24(2):195-206

Bern PA, Withers VR, Cairns RJR (1980) Wax deposition in crude oil pipelines. In: Eur. Offshore Pet. Conf. Exhib, pp 571-575

Binks BP, Fletcher PDI, Roberts NA, Dunkerley J, Greenfield H, Mastrangelo A et al (2015) How polymer additives reduce the pour point of hydrocarbon solvents containing wax crystals. Phys Chem Chem Phys, R Soc Chem 17(6):4107-4117

Bosh FG, Eastlund BJ (1992) Evaluation of downhole electric impedance heating systems for paraffin control in oil wells. IEEE Trans Ind Appl 28(1):190-195

Chen XT, Butler T, Volk M, Brill JP (1997) Techniques for measuring wax thickness during single and multiphase flow. In: Proc SPE Annu Tech Conf Exhib, pp 249-256

Chen X, Tsang Y, Zhang H-Q, Chen TX (2007) Pressure-wave propagation technique for blockage detection in subsea flowlines. In: SPE Annu Tech Conf Exhib [Internet]. https://www.onepetro. org/conference-paper/SPE-110570-MS. Accessed 10 Jan 2018

Chen W, Zhao Z, Yin C (2010) The interaction of waxes with pour point depressants. Fuel 89(5):1127-1132

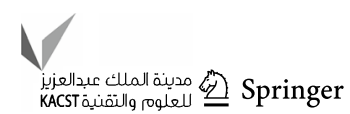


Chi Y, Daraboina N, Sarica C (2017) Effect of the flow field on the wax deposition and performance of wax inhibitors: cold finger and flow loop testing. Energy Fuels 31(5):4915-4924

Danilović DS, Karović Maričić VD, Čokorilo VB (2010) Solving paraffin deposition problem in tubing by heating cable application. Therm Sci 14(1):247-253

Del García MC, Carbognani L, Urbina A, Orea M (1998) Paraffin deposition in oil production. Oil composition and paraffin inhibitors activity. Pet. Sci Technol 16(9-10):1001-1021

Del García MC, Orea M, Carbognani L, Urbina A (2001) The effect of paraffinic fractions on crude oil wax crystallization. Pet Sci Technol 19(1-2):189-196

El-Gamal IM, Khidr TT, Ghuiba FM (1998) Nitrogen-based copolymers as wax dispersants for paraffinic gas oils. Fuel 77(5):375-385

Etoumi A, El Musrati I, El Gammoudi B, El Behlil M (2008) The reduction of wax precipitation in waxy crude oils by Pseudomonas species. J Ind Microbiol Biotechnol 35(11):1241-1245

Franconi NG, Bunger AP, Sejdić E, Mickle MH (2014) Wireless communication in oil and gas wells. Energy Technol 2(12):996-1005

Gonçalves JL, Bombard AJF, Soares DAW, Alcantara GB (2010) Reduction of paraffin precipitation and viscosity of Brazilian crude oil exposed to magnetic fields. Energy Fuels 24(5):3144-3149

Gonçalves JL, Bombard AJF, Soares DAW, Carvalho RDM, Nascimento A, Silva MR et al (2011) Study of the factors responsible for the rheology change of a Brazilian crude oil under magnetic fields. Energy Fuels 25(8):3537-3543

Guerreiro L, Carvalho CLB, Maciel C, Sousa J, Caetano H, Soares LP et al (2012) The challenge of developing complex marginal fields, example of NE Brazil. Abu Dhabi Int Pet Conf Exhib [Internet] 2012:0-12. https://doi.org/10.2118/162323-MS

Guo Y, Li W, Zhu L, Wang Z, Liu H (2012) Phosphoric chemical conversion coating with excellent wax-repellent performance. Appl Surf Sci 259:356-361

Haghighi H, Azarinezhad R, Chapoy A, Anderson R, Tohidi B (2007) Hydraflow: avoiding gas hydrate problems. SPE Int 107335:1-10

Hamida T (2007) Analysis of capillary interaction and oil recovery under ultrasonic waves. Transp Porous Media 70(2):231-255

Hamilton DS, Herman B (2011) The application of passive energy to production optimization; stabilizing the micelle structure in oil to prevent deposition of paraffin, asphaltenes, and mineral scale and reduce well-head viscosity in heavy oil. In: SPE Int (WVS 071), Proceedings of South American oil and gas congress. Maracaibo, Venezuela

He Z, Mei B, Wang W, Sheng J, Zhu S, Wang L et al (2003) A pilot test using microbial paraffin-removal technology in Liaohe oilfield. Pet Sci Technol [Internet] 21(1-2):201-210. http://www. scopus.com/inward/record.url?eid=2-s2.0-0037217453\&partn erID=tZOtx3y 1

He C, Ding Y, Chen J, Wang F, Gao C, Zhang S et al (2016) Influence of the nano-hybrid pour point depressant on flow properties of waxy crude oil. Fuel [Internet] 167:40-48. https://doi. org/10.1016/j.fuel.2015.11.031

Hou Y, Zhou R, Long X, Liu P, Fu Y (2015) The design and simulation of new downhole vibration device about acoustic oil recovery technology. Pet [Internet] (Elsevier Ltd) 1(3):257-263. http://linki nghub.elsevier.com/retrieve/pii/S2405656115000437. Acsessed 20 Mar 2018

$\mathrm{Hu} \mathrm{Z,} \mathrm{Wu} \mathrm{M,} \mathrm{Hu} \mathrm{K,} \mathrm{Liu} \mathrm{J} \mathrm{(2015)} \mathrm{Prediction} \mathrm{of} \mathrm{wax} \mathrm{deposi-}$ tion in an insulation crude oil pipeline. Pet Sci Technol 33(15-16):1499-1507

Irwin S (1955) Paraffin remover [Internet]. Google patents. https:// www.google.ch/patents/US2712853. Accessed 24 Jan 2018

Ismail L, Westacott RE, Ni X (2008) On the effect of wax content on paraffin wax deposition in a batch oscillatory baffled tube apparatus. Chem Eng J 137(2):205-213
Jalalnezhad MJ, Kamali V (2016) Development of an intelligent model for wax deposition in oil pipeline. J Pet Explor Prod Technol 6(1):129-133

Jennings DW, Breitigam J (2010) Paraffin inhibitor formulations for different application environments: from heated injection in the desert to extreme cold arctic temperatures. Energy Fuels 24(4):2337-2349

Jing G, Ye P, Zhang Y (2017) The action mechanism of wax inhibitors (WI) on pour point and viscosity of mixed waxy oil. Pet Chem [Internet] 57(3):293-298. https://doi.org/10.1134/S0965 544117020153

Kelland MA (2009) Production chemicals for the oil and gas industry. CRC Press, Boca Raton

Khandekar S (2015) Paraffins-101 Schlumberger [Internet]. https:// easttexas.spe.org/images/document/2015-Shekhar-Khandekar. pdf. Accessed 31 Dec 2018

Kovrigin L, Kukharchuk I (2016) Automatic control system for removal of paraffin deposits in oil well in permafrost region by thermal method. Chem Eng Res Des 115:116-121

Krasnov AN, Khoroshavina EA, Prakhova MY (2017) Preventing paraffination of pumping equipment of oil wells. Adv Eng Res 133(Actual Issues of Mechanical Engineering (Aime 2017)):370-375

Lazar I, Voicu A, Nicolescu C, Mucenica D, Dobrota S, Petrisor IG et al (1999) The use of naturally occurring selectively isolated bacteria for inhibiting paraffin deposition. J Pet Sci Eng 22(1-3):161-169

Li M, Su J, Wu Z, Yang Y, Ji S (1997) Study of the mechanisms of wax prevention in a pipeline with glass inner layer. Colloids Surf A Physicochem Eng Asp 123-124:635-649

Liang W, Zhu L, Xu C, Li W, Liu H (2016) RSC advances ecologically friendly conversion coatings with special wetting behaviors for wax prevention. RSC Adv [Internet] R Soc Chem 6:26045-26054. https://doi.org/10.1039/C6RA00611F

Lively G (2002) Flow assurance begins with downhole insulation. In: Offshore Technol Conf; paper no. OTC14118

Manka JS, Ziegler KL (2001) Factors affecting the performance of crude oil wax-control additives. In: Proceedings of SPE Prod Oper Symp [Internet] 639-645, SPE 67326-MS. http://www. scopus.com/inward/record.url?eid=2-s2.0-1642439280\&partn erID $=$ tZOtx3y1. Accessed 10 Jan 2018

Manka JS, Magyar JS, Smith RP (1999) Novel method to winterize traditional pour point depressants. In: SPE Int [Internet]. 1: SPE 56571-MS. http://www.scopus.com/inward/record.url?eid=2s2.0-0033344613\&partnerID=tZOtx3y1. Accessed 14 Jan 2018

Merino-Garcia D, Correra S (2008) Cold flow: a review of a technology to avoid wax deposition. Pet Sci Technol 26(4):446-459

Mullakaev MS, Abramov VO, Abramova AV (2015) Development of ultrasonic equipment and technology for well stimulation and enhanced oil recovery. J Pet Sci Eng [Internet] (Elsevier) 125:201-208. https://doi.org/10.1016/j.petrol.2014.10.024

Paso K, Kompalla T, Aske N, Rønningsen HP, Øye G, Sjöblom J (2009) Novel surfaces with applicability for preventing wax deposition: a review. J Dispers Sci Technol 30(6):757-781

Pedersen KS, Rønningsen HP (2003) Influence of wax inhibitors on wax appearance temperature, pour point, and viscosity of waxy crude oils. Energy Fuels 17(2):321-328

Quan Q, Wang W, Wang P, Yang J, Gao G, Yang L et al (2016) Effect of oil temperature on the wax deposition of crude oil with composition analysis. Braz J Chem Eng 33(4):1055-1061

Quenelle A, Gunaltun M (1987) Comparison between thermal insulation coatings for underwater pipelines, OTC 5500. Offshore Technol. Conf

Rana D, Bateja S, Biswas S, Kumar A, Misra T, Lal B (2010) Novel microbial process for mitigating wax deposition in down hole tubular and surface flow lines. In: Proc. SPE Oil Gas India Conf. 
Exhib. [Internet] (August). http://www.onepetro.org/mslib/servl et/onepetropreview?id=SPE-129002-MS\&soc $=$ SPE

Reistle CE. Jr, Blade OC (1932) Paraffin and congealing-oil problems, bulletin 348, University of North Texas Libraries, UNT Libraries Government Documents Department. Washington D.C. [Internet]. https://digital.library.unt.edu/ark:/67531/metad c12519/m2/1/high_res_d/Bulletin0348.pdf. Accessed Mar 2018

Ridzuan N, Adam F, Yaacob Z (2016) Evaluation of the inhibitor selection on wax deposition for Malaysian crude oil. Pet Sci Technol 34(4):366-371

Roberts PM, Venkitaraman A, Sharma MM (1996) Ultrasonic removal of organic deposits and polymer induced formation damage. In: SPE (SPE 31129), pp 571-578

Santamaria MM, George RE (1991) Controlling paraffin-depositionrelated problems by the use of bacteria treatments. In: SPE Annu Tech Conf Exhib. 6-9 October, Dallas, Texas. SPE-22851-MS, pp 352-361

Sarica C, Panacharoensawad E (2012) Review of paraffin deposition research under multiphase flow conditions. Energy Fuels 26:3968-3978

Sifour M, Al-Jilawi Majid H, Aziz Ghazi M (2007) Emulsification properties of biosurfactant produced from Pseudomonas aeruginosa RB 28. Pak J Biol Sci 10(8):1331-1335

Singh P, Walker J, Lee HS, Gharfeh S, Thomason B, Blumer D (2007) An application of vacuum-insulated tubing (VIT) for wax control in an arctic environment. In: SPE drill. Complet [Internet], vol 22(2), pp 127-36. http://www.scopus.com/inward/recor d.url?eid $=2$-s2.0-34447637454\&partnerID $=40 \& \mathrm{md} 5=37 \mathrm{~d} 20$ 9020e79f17e0614d879a2c4f5f8. Accessed 14 Jan 2018

Sood N, Lal B (2008) Isolation and characterization of a potential paraffin-wax degrading thermophilic bacterial strain Geobacillus kaustophilus TERI NSM for application in oil wells with paraffin deposition problems. Chemosphere 70(8):1445-1451

Straub TJ, Autry SW, King GE (1989) An investigation into practical removal of downhole paraffin by thermal methods and chemical solvents. In: SPE, SPE 18889

Sulaiman ADI, Ajienka AJ, Sunday IS (2011) Application of piezoelectric energy generated from quartz plus semiprecious metals on wax deposition control. J Pet Gas Eng 2(May):93-98

Sulaimon AA, Falade GK, Delandro W (2010) A proactive approach for predicting and preventing wax deposition in production tubing strings: a Niger delta experience. J Pet Gas Eng 1(4):26-36

Szilas AP (1975) Production and transport of oil and gas. Elsevier Scientific Publishing Company, New York

Tao R, Tang H (2014) Reducing viscosity of paraffin base crude oil with electric field for oil production and transportation. Fuel [Internet]. (Elsevier Ltd) 118(February):69-72. https://doi. org/10.1016/j.fuel.2013.10.056

Tao R, Xu X (2006) Reducing the viscosity of crude oil by pulsed electric or magnetic field. Energy Fuels 20(5):2046-2051

Thota ST, Onyeanuna CC (2016) Mitigation of wax in oil pipelines. Int J Eng Res Rev 4(4):39-47
Tiwari S, Verma SK, Karthik R, Singh AK, Kumar S, Kumar M (2014) In situ heat generation for near wellbore asphaltene and wax remediation. In: Int Pet Technol Conf p 9

Tukenov D (2014) Technology update: Nanochemistry drives new method for removal and control of wax. J Pet Technol 66(12):30-33

Vítkovský JP, Lee PJ, Stephens ML, Lambert MF, Simpson AR, Liggett JA (2003) Leak and blockage detection in pipelines via an impulse response method. Pumps Electromech Devices Syst Appl Urban Water Manag 1(January):423-430

Wang W, Huang Q (2014) Prediction for wax deposition in oil pipelines validated by field pigging. J Energy Inst [Internet] (Elsevier Ltd) 87(3):196-207. https://doi.org/10.1016/j.joei.2014.03.013

Wang K-S, Wu C-H, Creek JL, Shuler PJ, Tang Y (2003) Evaluation of effects of selected wax inhibitors on wax appearance and disappearance temperatures. Pet Sci Technol [Internet] 21(3-4):359368. https://doi.org/10.1081/LFT-120018525

Wang F, Zhang DM, Ding YF, Zhang LX, Yang MS, Jiang BL et al (2011) The effect of nanohybrid materials on the pour-point and viscosity depressing of waxy crude oil. Chin Sci Bull 56(1):14-17

Wang Z, Zhu L, Liu H, Li W (2013) A conversion coating on carbon steel with good anti-wax performance in crude oil. J Pet Sci Eng 112:266-272

Wei B, Lu L, Li H, Xue Y (2016) Novel wax-crystal modifier based on $\beta$-cyclodextrin: synthesis, characterization and behavior in a highly waxy oil. J Ind Eng Chem [Internet] Korean Soc Ind Eng Chem 43:86-92. https://doi.org/10.1016/j.jiec.2016.07.051

White M, Pierce K, Acharya T (2017) A review of wax-formation/ mitigation technologies in the petroleum industry. SPE Prod Oper [Internet]. https://doi.org/10.2118/189447-PA

Xiao M, Li W-H, Lu M, Zhang Z-Z, Luo Y-J, Qiao W et al (2012) Effect of microbial treatment on the prevention and removal of paraffin deposits on stainless steel surfaces. Bioresour Technol [Internet] (Elsevier Ltd) 124:227-232. https://doi.org/10.1016/j. biortech.2012.07.063

Yang F, Paso K, Norrman J, Li C, Oschmann H, Sjöblom J (2015) Hydrophilic nanoparticles facilitate wax inhibition. Energy Fuels 29(3): 1368-1374

Zhang X, Tian J, Wang L, Zhou Z (2002) Wettability effect of coatings on drag reduction and paraffin deposition prevention in oil. J Pet Sci Eng 36(1-2):87-95

Zyrin VO (2016) Electrothermal complex with downhole electrical heating generators for enhanced heavy oil recovery. Int J Appl Eng Res 11(3):1859-1866

Publisher's Note Springer Nature remains neutral with regard to jurisdictional claims in published maps and institutional affiliations 